\title{
Literatura, humanidade, humanização: a plenitude da condição humana
}

\author{
Arnaldo Vianna Neto ${ }^{a}$
}

\begin{abstract}
Resumo
Aborda-se neste artigo o ensino de literatura no Brasil no âmbito de uma releitura contemporânea da complexa rede de relações tecida em torno das situações educativas que compõem o sistema educacional brasileiro. Nesse sentido, destaca-se a importância da reelaboração de determinados conceitos cuja leitura não pode ser outra senão a da complexidade e do inacabamento, como os de humanização, humanidade e literatura, entre outros. Destaca-se também a necessidade de multiplicação de políticas institucionais visando a reunir a população de profissionais da educação e estudantes brasileiros em torno de um programa nacional de revisão do contex to educativo. Nesse quadro, inscreve-se uma avaliação do desempenho da universidade no que se refere à repercussão da investigação acadêmica nas práticas de ensino, no processo de elaboração curricular, na reformulação de projetos curriculares dos diversos sistemas educacionais e programas de ensino de instituições educacionais.
\end{abstract}

Palavras-chave: Humanidades - Humanização Leitor - Literatura - Universidade 
Em um momento em que se discutem as culturas pós-industriais e a desconstrução dos conceitos de utopia que atravessaram o século $X X$, uma interrogação fundamental se inscreve como centro das políticas de identidade que se produzem como projeção do pensamento que deverá reger o terceiro milênio: que homem ou que humanidade emergirá dos limites da normalidade invadidos pela cibernética, pela produção da inteligência artificial?

A sociedade virtual em construção, na qual a formação dos quadros coletivos é afetada pela vertiginosa mutação em curso das formas de comunicação e informação, produz uma cartografia sociopolítica que inscreve o homem como ator de sua alteridade nesse processo de transcodificação das realidades atuais em direção ao virtual. Nesse quadro, a dinâmica da mutação econômica e cultural, provocada pela virtualização, anuncia uma crise civilizacional, já evidenciada no rigor filosófico de sua concepção como jogo de criação aberto no processo de transformação de um modo de ser em outro, sem riscos de desrealização, sem oposição ao real, mas emergindo necessariamente dele para garantia da continuidade da aventura humana.

Ante tais projeções construídas pela revolução termonuclear que, como sequência da revolução industrial na Europa ocidental, agenciou alterações fundamentais na ordem política e na visão de mundo planetária, provocando imensas transformações na vida material de todos os povos, questiona-se o futuro das humanidades não inscritas como agentes na história ocidental. A manutenção da ideologia comunicacional pelos meios de telecomunicação de massa perpetuará o produto da eletrônica e da automação, dos sistemas cibernéticos de coordenação de informações, da tecnologia dos transistores que produziu o radar, o computador e a nova robótica, até que limites?

É nesse contexto mundial, definido por Ferreira Gullar como "banal e delirante, onde se torna cada dia mais clara a necessidade de despertar e cultivar o que há de humano no homem" (1989, p.15), que a morte do escritor Ariano Suassuna, ocorrida em 23 de julho de 2014, durante a escrita deste artigo, reabre a discussão acadêmica sobre a importância da reelaboração de determinados conceitos paradigmáticos cuja leitura não pode ser outra senão a da complexidade e do inacabamento, 
como os de humanização, humanidade e literatura, entre outros. A perplexidade do escritor ante a "pobre e triste condição do homem" em sua solitária travessia existencial, condenado à contingência da morte, definida por ele como "o único mal irremediável, aquilo que é a marca do nosso estranho destino sobre a terra, aquele fato sem explicação que iguala tudo o que é vivo num só rebanho de condenados, porque tudo o que é vivo, morre" (SUASSUNA, 1975, p. 175-76), revela um exercício dialógico sobre o conceito de humanidade. À condenação ao cumprimento da sentença definida pelo significado transcendental da vida, determinada pela contingência da morte, que ele define como o inevitável da condição humana, o escritor responde com a prática da literatura. Em agosto de 2013, ao inaugurar a exposição intitulada Ariano Suassuna - Arte como missão na Caixa Cultural do Rio de Janeiro e se apresentar em uma de suas aulas-espetáculo no Teatro Municipal, Suassuna declarou que enfrentava a vida e desafiava a morte com literatura, definindo sua obra como missão, vocação e festa:

Em primeiro lugar, minha literatura é uma missão: defender o povo e a cultura brasileiros. Em segundo, uma vocação. Não acredito em literatura sem vocação. Em terceiro, é uma festa. Passei por momentos muito duros na vida, mas os enfrentei pela minha arte, que é a minha dança. [...] Quando digo dançar, quero dizer que participo da festa da literatura. [...] A tarefa de viver é dura, mas fascinante. [...] É com essas três palavras que eu danço: missão, vocação e festa. (Jornal O Globo, Segundo Caderno, p.10, 04/08/2013)

Citando o medo da morte como condição humana anunciada pela fome, pelo sofrimento, pela solidão, na cena do julgamento final do Auto da Compadecida, Suassuna exercita seu conceito de humanização, justificando a prática de "atos vergonhosos" como determinação da tragédia humana:

Compadecida: É verdade que eles praticaram atos vergonhosos, mas é preciso levar em conta a pobre e triste condição do homem. [...] Quase tudo o que eles faziam era por medo. Eu conheço isso, porque convivi com os homens: começam com medo, coitados, e terminam por fazer o que não presta, quase sem querer. É medo. Encourado: Medo? Medo de quê? Bispo: Ah, senhor, de muitas coisas. Medo da morte... Padre: Medo do sofrimento... Sacristão: Medo da fome... Padeiro: Medo da solidão. (SUASSUNA, 1975, p. 175-76) 
Nas citações, pode-se entrever o papel da literatura como disciplina cultural, realizando-se como atividade artística produzida pela linguagem e integrando um conjunto de expressões culturais que constituem o conceito de humanidade como resultante da atividade humana. Em sua concepção de literatura como uma forma de conhecimento da totalidade humana, Suassuna exercita o conceito de que "uma obra é universal na medida em que contém uma quantidade maior de sonho humano" (2014).

Denuncia-se ainda, na obra de Suassuna, a política planetária centrada em um poder econômico reitor de onde se excluem as novas categorias de pensamento que emergem de formações socioculturais cuja condição humana foi profundamente violentada nesse processo de seleção universal progressiva. Na metáfora literária do escritor, problematizam-se tanto os grandes discursos históricos, filosóficos e científicos, como os sistemas de pensamento anexos às noções de verdade logocêntrica. O escritor desconstrói o consenso de autoridade hegemônica ocidental no qual se mantém uma episteme específica formulada por teorias de produção e representação que tenta manter uma eficácia simbólica centrada nas tecnologias da virtualidade, cujo investimento se estrutura na constituição das figuras da virtualidade, ou seja, na criação de seres eletrônicos que atuam como semideuses na construção da utopia do terceiro milênio: a transformação radical da humanidade. Nesse quadro, impõe-se uma opção maniqueísta: ou se provoca uma revisão dos códigos de valor de nosso século, planejando-se conscientemente uma civilização humana comum, relacional e não competitiva, compatível com o fantástico saldo de conhecimento tecnológico acumulado, capaz de realizar utopias de equidade e fartura, ou se desencadeia um processo de deterioração sociocultural profundo. Nesse sentido, Darcy Ribeiro, em seu romance confessional, Migo, manifesta-se sobre o papel do intelectual brasileiro na desconstrução dos paradigmas ocidentais, da qual emerge o caos existencial resultante das assimetrias produzidas pelo sistema eurocêntrico de poder e outros mecanismos internacionais:

Que intelectualidade é esta nossa? De quem ela é? Supostamente somos a inteligência do povo brasileiro [...]. Os educados, os lidos, os competentes, os bonitos, [...] serviçais fiéis da ordem. Nós, intelectuais, nos pagando com palavras 
de discursos literários [...]. O desencontro é total. Nossa vanguarda lúcida, fiel a seu povo, não existe. O povo brasileiro está órfão. É um corpo sem cabeça. Nós, intelectuais, sem um povo com que nos identifiquemos, com horror do povo de verdade que aí está, somos uma cabeça decepada. (1988, p. 35)

Embora universalizada nas matrizes culturais determinantes das relações com o lugar histórico que ocupamos como sujeitos sociais, a arqueologia etimológica da literatura contém o princípio da dispersão, ou seja, o movimento do próprio étimo é responsável pela circulação de seus sentidos entre sujeitos mediados pela linguagem em seu diálogo com o mundo. Definindo-se o ato de escrever como o estar em um outro lugar, ou seja, no espaço imaginário da criação, não se pode ignorar hoje o diálogo da literatura com questões relativas à passagem da civilização da escrita à era da imagem eletrônica, visual e auditiva, capaz de modificar a relação humana com o tempo e o espaço. No trânsito do inteligível ao sensível, ao sensorial, quando a tecnologia instaura o visível em contraponto com o legível, há que se discutir a realidade histórica, o processo cultural no qual a universalização, sustentada pela saturação imposta pelas técnicas eletrônicas de difusão dos meios de comunicação, determina a padronização do gosto, da cultura.

A presença massificante dos meios de comunicação eletrônica telegênica, por seu poder de opressão e violação constantes do ethos humano, está moldando não só a vida social, mas também a psicologia humana, provocando um entorpecimento passivo tanto nas massas populares como nas novas gerações. Esse fenômeno, ou seja, essa "revolução" informática e eletrônica, problemática e comprometedora, exige dos sistemas educacionais um compromisso ético com o humano, ou seja, a revisão da educação à luz das novas linguagens. Isso nos leva a repensar a memória, a noção de pertencimento e o conceito de solidariedade no exercício dialógico entre o eu individual e o nós coletivo.

É nesse sentido que se interroga a concepção da literatura como construção histórico-social na qual se realizam os conceitos de humanidade, humanismo e humanização, como quer Antonio Candido em $O$ direito à literatura:

A literatura [...] é fator indispensável de humanização e, sendo assim, confirma o homem na sua humanidade [...]. En- 
tendo por humanização o processo que confirma no homem aqueles traços que reputamos essenciais, como o exercício da reflexão, a aquisição do saber, a boa disposição para com o próximo, o afinamento das emoções, a capacidade de penetrar nos problemas da vida, o senso da beleza, a percepção da complexidade do mundo e dos seres, o cultivo do humor. A literatura desenvolve em nós a quota de humanidade na medida em que nos torna mais compreensivos e abertos para a natureza, a sociedade, o semelhante. (2004, p.180)

\section{A literatura como disciplina}

Ao reconhecer a oposição histórica entre a humanização e a desumanização do homem, Paulo Freire define o ser humano como um ser inacabado em processo constante de humanização. O conceito de sua Educação Libertadora é o de humanização do ser humano, ou seja, a passagem de uma consciência ingênua a uma consciência crítica capaz de tornar os educandos sujeitos do processo educativo bem como de sua própria história. Entendendo humanização como processo de desenvolvimento da essencialidade humana, ou seja, a ação de tornar humano, ou mais humano, o humano, no desempenho de seu papel social em relação à comunicação, crenças, valores, normas e regras que orientam a vida no processo de construção gradual do compartilhamento de conhecimentos e sentimentos, Antonio Candido ensina, em $O$ direito à literatura, que o acesso à literatura, em todas as modalidades e em todos os níveis, é "um direito inalienável" (p.191) de todo ser humano e fator indispensável para o processo de humanização. Também Derrida, em A universidade sem condição (2003), ao avaliar o lugar das artes e das humanidades na Universidade contemporânea, define a literatura como instituição democrática e Edgar Morin defende a valorização de uma cultura humanística para situar a condição humana no mundo, integrando a "contribuição inestimável das humanidades, não somente a filosofia, a história, mas também a literatura, a poesia, as artes" (MORIN, 2000, p.46). Também se lê em Literatura para quê, o manifesto de Antoine Compagnon sobre a literatura como instrumento cultural de humanização:

Primeiramente, em um sentido bastante simples, viver é mais fácil [...] para aqueles que sabem ler não somente as informações, os manuais de instrução, as receitas médicas, os jornais 
e as cédulas de voto, mas também a literatura. Além disso, supôs-se por muito tempo que a cultura literária tornasse o homem melhor e lhe desse uma vida melhor. (2009, p. 29)

Ao se tomar, como referencial teórico, o princípio de que a literatura é um sistema aberto, não se encerrando, portanto, nos limites de sua literariedade textual, pode-se defini-la, em sua inscrição sócio-histórica, como parte de um dispositivo de comunicação, como já postulava Mikhail Bakhtin em 1920, antecipando-se o dialogismo do autor soviético às reflexões sobre a intertextualidade do final dos anos setenta. Integrando-se, pois, a um sistema de comunicação, a literatura não é, como quer Derrida, expressão de uma totalidade, mas um ato democrático de comunicação, em que se referenciam, por determinação histórica, contradições ideológicas e materiais responsáveis por sua produção. A visão de Derrida, a de Antonio Candido e a de Bakhtin sobre as relações entre texto e contexto, assim como a visão de Bakhtin e Hans Robert Jauss sobre a historiografia literária deveriam constituir as bases teóricas para a formulação de uma nova proposta de ensino de literatura. É nesse âmbito que a questão do ensino de literatura ganha legitimidade. As experiências de ensino e pesquisa em literatura, marcadas pela responsabilidade de se formar uma concepção democrática e socializante do papel da Escola em nossas sociedades, remetem à questão da transmissão de um universo cultural de crenças e práticas multiculturais como herança identitária.

Em relação ao ensino de literatura no Brasil, lugar de nossas práticas educacionais, é preciso dizer que, hoje, a literatura não ocupa um lugar privilegiado. Essa tendência poderia ter sido atenuada pelo investimento em iniciativas políticas e parcerias administrativas estratégicas na rede educacional, visando à valorização das trocas educativas entre parceiros institucionais. No momento em que se refazem caminhos para o ensino de literatura no sistema escolar brasileiro, é importante privilegiar não só uma aprendizagem que não seja superficial nem se limite apenas à aquisição de referências informativas, mas também a apreensão rigorosa de todas as competências textuais/literárias (ler e produzir literatura) ou do desenvolvimento do gosto estético pelo objeto literário, que considere os aspectos cultural, comunicacional, metalinguístico, meta- 
literário e metadiscursivo. Nesse âmbito, inscrevem-se Jauss, Iser, Gumbrecht, Barthes, entre outros teóricos da "estética da recepção", os quais têm o mérito de analisar o papel do leitor como parte do processo de produção literária, conceito antecipado por Jean-Paul Sartre em Qu'est-ce que la littérature?, escrito em 1948. Na concepção de Iser (1999), ao possibilitar a criação de suplementos de leitura, a literatura é um dos objetos de conhecimento fundamentais ao processo de formação humana.

Em Lector in fabula (2004), Humberto Eco teoriza sobre a cooperação interpretativa no texto narrativo, ou seja, sobre a cooperação entre texto e leitor, partindo do conceito de literatura como obra aberta, antecipado em seu Opera aperta como um ato de comunicação ou de cooperação textual. A Estética da Recepção tece uma relação dialética entre autor, obra e leitor, privilegiando o leitor como produtor do texto artístico e considerando a obra de arte como um sistema definido por produção, recepção e comunicação. Destaca-se ainda, na Estética da Recepção, o interesse pelas condições sócio-históricas que formulam as diversas interpretações que a obra recebe, assinalando-se o discurso como resultado de um processo de recepção que movimenta a pluralidade dessas estruturas de sentidos historicamente mediadas.

Os conceitos de literatura como "logro magnífico que permite ouvir a língua fora do poder, no esplendor de uma revolução permanente da linguagem" (BARTHES, 1980, p.12) e como "instituição democrática" (DERRIDA, 2003, p. 25) atuam como desafios educacionais inscritos em um quadro de complementaridade entre os significados político e pedagógico da literatura e sua contribuição para a formação acadêmica na perspectiva da emancipação humana. Para tanto, é necessária a desconstrução do conceito das Humanidades e seus antigos cânones, como se lê em $A$ universidade sem condição de Jacques Derrida:

[...] não se trata mais somente do conceito conservador e humanista a que se associam com frequência as Humanidades e seus antigos cânones - os quais, não obstante, a meu ver, devem ser protegidos a todo custo. Permanecendo ao mesmo tempo fiel à tradição, esse novo conceito das Humanidades deveria incluir ainda o direito, as teorias da tradução, além do que se chama em cultura anglo-saxã, da qual é uma das formações originais, a "theory" (articulação original de te- 
oria literária, de filosofia, de linguística, de antropologia, de psicanálise, etc), mas também, certamente, em todos esses lugares, as práticas desconstrutivas. (DERRIDA, 2003, p. 25)

Derrida reconhece a liberdade, a autonomia, a resistência e a dissidência como princípios característicos do saber acadêmico e considera, como "lugar privilegiado de apresentação, de reelaboração e de discussão temática" (2003, p. 25), o campo das Humanidades, defendendo "uma certa independência incondicional do pensamento, da desconstrução, da justiça, das Humanidades, da Universidade [...] dissociada de toda fantasia de soberania indivisível e de mestria soberana" (2003, p. 80), comprometendo neste processo não apenas a literatura, mas também o ato de professar ou a "profissão de fé" com toda a carga semântica que a expressão carrega:

Por que relacionar tudo isso com insistência não somente à questão da literatura, dessa instituição democrática que se chama literatura, ou ficção literária, a um certo simulacro e a um certo "como se", mas à questão da profissão de fé e de seu porvir? (DERRIDA, 2003, p. 25)

\section{Universidade: cidadela exposta ou lugar de resistência crítica?}

Em A Universidade sem condição, Derrida afirma que, "em princípio, e conforme sua vocação declarada, em virtude de sua essência professada, ela [a Universidade] deveria permanecer como um derradeiro lugar de resistência crítica - e mais que crítica - a todos os poderes de apropriação dogmáticos e injustos" (2003, p.16). No desdobramento da série de proposições que compõem sua tese, Derrida propõe a ampliação e a reelaboração do conceito das Humanidades e seus cânones, nos quais se inscrevem os discursos da socialidade, a teoria literária, a filosofia, a linguística, a antropologia, a psicanálise, o direito, a ciência política, a história etc, os quais têm como lugar privilegiado de discussão, "incondicional e sem pressuposto", a Universidade e, nela, os Departamentos pertencentes às Humanidades, incluindo-se "certamente, em todos esses lugares, as práticas desconstrutivas" (DERRIDA, 2003, p. 25).

Situando a Universidade como elemento indispensável à produção dos saberes que constituem o pensamento sobre $\mathrm{a}$ 
humanidade do homem, "o próprio do homem", rede conceitual em que se funda o Humanismo, a Humanização e as Humanidades, Derrida elabora "um compromisso declarativo, um apelo em forma de profissão de fé: fé na Universidade e, nela, fé nas Humanidades de amanhã" (2003, p. 13). Sua profissão de fé é acompanhada de uma pergunta:

[...] pode a Universidade (e de que maneira?) afirmar uma independência incondicional, reivindicar uma forma de soberania, [...] sem nunca se arriscar ao pior, a saber, [...] ter que se render e capitular sem condição, deixar-se conquistar ou comprar a qualquer preço? (DERRIDA, 2003, p. 21-2)

Na sequência da análise proposta, revela-se o vetor principal de sua tese: situar a condição humana no mundo contemporâneo, ou seja, analisar as formas de pensar o mundo em que o homem vive e onde luta por alcançar o grau de humanidade no qual se realizará em plenitude sua condição humana. Entre os agentes institucionais que intensificam a discussão em torno do humanismo contemporâneo, ponto fundamental para a instituição de um amplo debate de ideias sobre Educação, inscreve-se, como dever, a Universidade. Nesse quadro, em que se configuram valores individuais e coletivos produzidos pela evolução do pensamento social e científico, essencial ao progresso cultural, inclui-se, como propõe Derrida, a desconstrução do conceito de soberania relativos ao sujeito ou ao cidadão em geral, supostos "soberanos" enquanto tais, ou seja, livres e responsáveis.

Em 1978, a Editora Civilização Brasileira, ao lançar a coleção Encontros com a civilização brasileira, abre seu primeiro número com o artigo de Darcy Ribeiro intitulado Sobre o óbvio, no qual o antropólogo, ao analisar historicamente a matriz educacional brasileira, ensina que a primeira universidade brasileira foi criada por decreto em virtude da visita do rei da Bélgica ao Brasil em 1923. O protocolo oficial, que determinava a outorga do título de Doutor Honoris Causa ao rei, a ser cumprido pelo Itamaraty, só se realizaria, evitando um constrangimento à diplomacia brasileira, com a criação da Universidade do Brasil: "Assim foi criada a primeira universidade brasileira. Uma universidade que, desde então, se vem estruturando e desestruturando, como se sabe" (1978, p.20), informa ironicamente Darcy Ribeiro. No mesmo artigo, o 
autor registra que, à época, se contava com mais de cinquenta universidades e milhares de cursos superiores frequentados por mais de um milhão de jovens:

São tantos que já há quem diga que nossas universidades enfrentam uma verdadeira crise de crescimento, asseverando mesmo que seu único problema decorre de haver matriculado gente demais. Teriam elas crescido com tanta demasia que, agora, não podendo digerir o que têm na barriga, jibóiam. (RIBEIRO, 1978, p.20)

Avaliando que o conceito de crise de crescimento não expressava o fenômeno, o antropólogo afirma que:

O que ocorre com a universidade no Brasil é mais ou menos o que sucederia com uma vaca se, quando bezerra, ela fosse encerrada numa jaula pequenina. A vaca mesmo está crescendo naturalmente, mas a jaula de ferro aí esta, contendo, constringindo. Então o que cresce é um bicho raro, estranho. Este bicho nunca visto é o produto, é o fruto, é a flor acadêmica dessa classe dominante sábia, preclara, admirável que temos, que nos serve e a que servimos patrioticamente contritos. (RIBEIRO, 1978, p.20-1)

A crítica de Darcy Ribeiro dirige-se ao domínio da educação pelas classes dominantes e "sua extraordinária astúcia na defesa de seus interesses" $(1978$, p.21).

\section{Conclusão}

Neste artigo, foram abordadas algumas reflexões sobre o ensino da literatura, tomando-se a condição humana como elemento fundamental de discussão acadêmica. Concebida no contexto atual como fator de humanização, conceituou-se a literatura não apenas como um direito, mas também como mediadora do equilíbrio entre o homem e a sociedade, sabendo-se que um estudo atual sobre o panorama do ensino de literatura no Brasil não pode deixar de se inscrever no quadro das pesquisas sobre a complexa rede de relações tecida em torno das situações educativas que devem compor o sistema educacional brasileiro. A multiplicação de políticas institucionais visando a reunir a população de profissionais da educação e estudantes brasileiros em torno de um programa nacional de investigação do contexto educativo é um desafio a ser superado. Nesse sen- 
tido, há que se promover um profundo debate nacional sobre determinados conceitos cuja leitura não pode ser outra senão a da complexidade e do inacabamento.

Partindo-se da relação dialógica entre as séries discursivas, paralelamente aos fundamentos teóricos, metodológicos, e às reflexões didáticas sobre o ensino de literatura, não se pode deixar de inserir e privilegiar o diálogo político construído em torno das transformações sofridas por sociedades redefinidas no quadro do processo de integração regional, no qual se produzem embates ideológicos e se discutem políticas de oposição às ideologias homogeneisantes. Essa reflexão se refere a uma tomada de consciência socioeconômica, e sobretudo política, do papel que a produção de conhecimento e a partilha de saberes devem desempenhar em um contexto cultural em que se que privilegia o ideal da diversidade humana e do dialogismo em torno da humanização e das humanidades. Nesse quadro, o planejamento de políticas culturais eficazes em nível nacional, incluindo a rede universitária, deve desempenhar seu papel.

Concluindo-se, não se pode deixar sem registro as influências, no planejamento curricular, dos documentos oficiais mais conhecidos sobre a concepção de ensino de literatura como formação do estudante para o exercício da cidadania, como a Lei 9394/96, em cujo texto se definem as Diretrizes e Bases da Educação Nacional instauradas pelo Governo brasileiro quando da aprovação da LDB pelo Congresso em 20 de dezembro de 1996 e os documentos recentemente publicados pelo MEC, como os Parâmetros Curriculares Nacionais - Ensino Médio (PCNEM) e os Parâmetros Curriculares Nacionais + Ensino Médio (PCN+).

\section{REFERÊNCIAS}

BAKHTIN, Mikhail. Estética da criação verbal. Tradução de Maria Ermantina Galvão G. Pereira. São Paulo: Martins Fontes, 1997. Questões de literatura e de estética. A teoria do romance.

Tradução de Aurora Fornoni Bernardini et al. São Paulo: Hucitec / UNESP, 1988. Aula. São Paulo: Cultrix, 1980. 
BARTHES, Roland. Da obra ao texto. O rumor da língua. Tradução de Mário Laranjeira. São Paulo: Martins Fontes, 2004. BENJAMIN, Walter. A obra de arte na época de sua reprodutibilidade técnica. Tradução de Carlos Nelson Coutinho. In: LIMA, Luiz Costa (org.). Teoria da Cultura de Massa. Rio de Janeiro: Saga, 1969. (Idéias e Fatos Contemporâneos, 28)

Magia e técnica, arte e política: ensaios sobre literatura e história da cultura. (Obras escolhidas, vol. 1) Tradução de Sérgio Paulo Rouanet. $7^{a}$ ed. São Paulo: Brasiliense, 1994.

BOSI, Alfredo. Cultura brasileira, culturas brasileiras. In: Dialética da colonização. São Paulo: Companhia das Letras, 1992. BOURDIEU, Pierre. Escritos de educação. Petrópolis: Vozes, 1998.

As regras da arte: gênese e estrutura do campo literário. São Paulo: Companhia das Letras, 1996.

CANDIDO, Antonio. O direito à literatura. In: . Vários escritos. São Paulo: Duas Cidades, 1995/2004. Formação da literatura brasileira. Rio de Janeiro: Itatiaia, 2000. CHARTIER, Roger. A aventura do livro. Do leitor ao navegador. São Paulo: UNESP / Imprensa Oficial do Estado, 1999.

COMPAGNON, Antoine. Literatura para quê? Tradução de Laura Taddei Brandini. Belo Horizonte: Editora UFMG, 2009. COMPAGNON, Antoine. O demônio da teoria: literatura e senso comum. $3^{\text {a }}$ ed. Tradução de Cleonice Paes Barreto Mourão e Consuelo Fortes Santiago. Belo Horizonte: EDUFMG, 2001. DENIS, Benoît. Literatura e engajamento: de Pascal a Sartre. Tradução de Luiz Dagobert de Aguirra Roncari. Bauru, SP: EDUSC, 2002.

DERRIDA, Jacques. A universidade sem condição. Tradução de Evando Nascimento. São Paulo: Editora Estação Liberdade, 2003. ECO, Umberto. Obra aberta: forma e indeterminação nas poéticas contemporâneas. Tradução de Giovanni Cutolo. São Paulo: Perspectiva, 1981. (Col. Debates, 4)

. Sobre a literatura. Ensaio. Rio de Janeiro: Record, 2003. . Lector in fabula. A cooperação interpretativa nos textos narrativos. Tradução de Attílio Cancian. São Paulo: Perspectiva, 2004. 
FARIA, Maria Alice. Parâmetros curriculares e literatura. As personagens de que os alunos realmente gostam. São Paulo: Contexto, 1999.

ISER, Wolfgang. $O$ ato da leitura: uma teoria do efeito estético. Tradução de Johannes Kretschmer. Vols. 1-2. São Paulo: Editora 34, 1996/1999.

. L'acte de lecture. Liège: Mardaga, 1976.

JAUSS, Hans Robert. Pour une esthétique de la réception. Traduit de l'allemand par Claude Maillard. Préface de Jean Starobinski. Paris: Gallimard, 2001. (Collection Tel, no. 169)

A estética da recepção: colocações gerais. In: LIMA, Luiz Costa (Seleção, coordenação e tradução). A literatura e o leitor: textos de estética da recepção. 2. ed. Rio de Janeiro: Paz e Terra, 2002. p. 67-84

O prazer estético e as experiências fundamentais da poiesis, aisthesis e katharsis. In: LIMA, Luiz Costa (Seleção, coordenação e tradução). A literatura e o leitor: textos de estética da recepção. 2. ed. Rio de Janeiro: Paz e Terra, 2002. p. 85-103 LEAHY-DIOS, Cyana. Lingua e literatura: uma questão de educação? Campinas: Papirus, 2001.

LIMA, Luiz Costa. A literatura e o leitor. $2^{\mathrm{a}}$ ed. Rio de Janeiro: Paz e Terra, 2002.

LIMA, Luiz Costa (Org.). A Literatura e o leitor: textos de estética da recepção. Rio de Janeiro: Paz e Terra, 1979.

MINISTÉRIO DA EDUCAÇÃO E CULTURA (MEC). Lei de diretrizes e bases da educação. São Paulo: FEPESP, 1996.

Diretrizes curriculares nacionais para o ensino médio. Brasília: MEC / CNE, 1998.

. Parâmetros curriculares nacionais: ensino médio. Linguagens, códigos e suas tecnologias. Brasília: Ministério da Educação / Secretária de Educação Média e Tecnológica, 1999. MORIN, Edgar. A cabeça bem feita: repensar a reforma, repensar o ensino. Tradução de Eloá Jacobina. Rio de Janeiro: Bertrand Brasil, 2005. 
Ensinar a condição humana. In: Os sete saberes necessários à educação do futuro. São Paulo: Cortez / Brasília / DF: UNESCO, 2000.

NOVAES, Adauto. (Org.). O silêncio dos intelectuais. São Paulo: Companhia das Letras, 2006.

RIBEIRO, Darcy. O processo civilizatório. Petrópolis - RJ: Editora Vozes / São Paulo: Círculo do Livro S/A, 1978. . Sobre o óbvio. In: SILVEIRA, Ênio, FÉLIX, Moacyr. (Eds). Encontros com a civilização brasileira. Rio de Janeiro: Civilização Brasileira, 1978. (Coletânea I) . Migo. Rio de Janeiro: Editora Guanabara, 1988. O Brasil como problema. Rio de Janeiro: Francisco Alves, 1995.

SARTRE, Jean-Paul. O que éliteratura? Tradução de Carlos Felipe Moisés. São Paulo: Editora Ática, 2004.

SERNA, Jorge Ruedas. (Org.). História e literatura: homenagem a Antonio Candido. Campinas: Editora da UNICAMP / Fundação Memorial da América Latina / São Paulo: Imprensa Oficial do Estado, 2003.

SUASSUNA, Ariano. Auto da Compadecida. Rio de Janeiro: AGIR Editora, 1975.

A arte popular do Brasil. Rio de Janeiro: Revista Brasileira de Cultura, 2: 37, 1969. 


\section{Abstract \\ Literature, humanity, humanization: the completeness of human condition}

This article addresses the teaching of literature in Brazil within a picture of a contemporary reimagining the complex network of relationships woven around the educational situations that compose the Brazilian educational system. In this sense, stands out the importance of the revision of certain concepts whose reading cannot be other than the complexity and state of unaccomplishment, like those of humanization, humanities and literature, among others. Also highlights the need for multiplication of institutional policies aiming to gather the professionals of education and Brazilian students around a national program to review the educational context. This picture also pretends to evaluate the performance of the University regarding academic research impact on teaching practices, in the curricular development process, in the redesign of various curricular project, educational systems and educational institutions curricula.

Keywords: Humanities - Humanization - Reader - Literature - University 